\title{
Nesne Ontolojisi, Varlıksal Öndayanaklar ve Bağımsız Mantiklar
}

\section{Ontology of Objects, Existential Assumptions and Free Logics}

\author{
Oğuz Akçelik ${ }^{1}$ (1)
}

'Arş. Gör., Orta Doğu Teknik Üniversitesi, Felsefe Bölümü, Sistematik Felsefe ve Mantık Anabilim Dalı, Ankara, Türkiye

\section{ORCID: O.A. 0000-0002-2617-395X}

Sorumlu yazar/Corresponding author: Oğuz Akçelik,

Orta Doğu Teknik Üniversitesi, Felsefe Bölümü, Sistematik Felsefe ve Mantık Anabilim Dalı, Ankara, Türkiye

E-mail/E-posta: akcelik@metu.edu.tr

Başvuru/Submitted: 18.11.2019

Revizyon Talebi/Revision Requested: 08.12.2019

Son Revizyon/Last Revision Received: 11.12.2019

Kabul/Accepted: 13.12.2019

\section{Atıf/Citation:}

Akcelik, Oguz. (2019). "Nesne Ontolojisi, Varlıksal Öndayanaklar ve Bağımsız Mantıklar" Felsefe Arkivi-Archives of Philosophy, 51: 1-16. https://doi.org/10.26650/arcp2019-5101

\begin{abstract}
ÖZET
Modern mantıkta nicelemenin yapıldığı değer kümesi içinde her tekil terimin bir nesneye gönderimde bulunması gerekir. Bu, yüklemler, niceleme ve özdeşlik mantığının temel öndayanağıdır. Fakat bu durum, ifade edilebilirlik problemlerine ve çıkarım düzen dışııklarına neden olur. Bağımsız mantık dizgeleri, boş tekil terim olarak adlandırılan ve herhangi bir gerçek nesneye gönderimde bulunmayan terimlerin yer aldığı önermelerin geçtiği argümanların çözümlenmesi ve geçerliliğinin sınanması için oldukça faydalı bir araçtır. Bu çalışmada bağımsız mantıkların dizgesel tanımlarını ve kaplamsal yorumlamalarını ele alacağız. Modern mantığın bir yönelimi olarak varlıksal öndayanaklardan bağımsız mantık dizgeleri, varlık olma niteliğini salt mantıksal zorunluluk olarak ele almaz. Bunun yerine ontolojik bir olanaklılık olarak ele alarak boş terimlerin geçtiği önermelerin kaplamsal yorumlamalarını mümkün kılar.
\end{abstract}

Anahtar Kelimeler: Varlıksal öndayanaklar, kaplamsal yorumlamalar, geçerlilik, bağımsız mantıklar, ontolojik olanaklılık

\section{ABSTRACT}

In modern logic, each singular term must denote an object in the domain of quantification. This is due to the ontological assumptions of first order quantification logic with identity. However, this results in certain anomalies, i.e. expressibility and validity of inference problems. Free logic is a useful tool to analyze propositions and test the validity of arguments containing empty singular terms which have no referent in the domain of quantification. In this study, we will examine systematic definitions and extensional interpretations of free logics. One of the most promising future orientations of modern logic, free logic as a logic free of existential assumptions, does not take the concept of existence as a logical necessity. Instead, the fundamental assumption is that of ontological possibility, and hence it will be possible for propositions containing empty terms to have extensional interpretations.

Keywords: Existential assumptions, extensional interpretations, validity, free logics, ontological possibility 


\section{Giriş}

Doğal dilin kullanıcıları nesneler hakkında konuşur. "Sokrates bir filozoftur", "Venüs bir gezegendir” gibi örnekler var olan nesnelere dair önermelerdir. Bu önermelerin dilsel yapısı, gerçekte var olan nesneler ve bu nesnelere yüklenen özellikler hakkında bir yargı bildirir. Benzer şekilde doğal dilin kullanıcıları gerçekte var olmayan nesneler hakkında da konuşabilir. Mitolojinin veya hayal gücünün nesneleri ve varsayımsal nesneler buna bir örnektir. "Pegasus kanatlı bir attır”, "Dünya’nın yörüngesinde Vulkan Gezegeni’ne bağlı herhangi bir sapma gözlemlenmemiştir” gibi önermeler gerçekte var olmayan nesneler ve bu nesnelere yüklenen özellikler hakkında birer yargı bildirir.

Modern mantık olarak tanımladığımız mantık dizgesi Frege sonrası mantık dizgesine atfen ortaya konulan yüklemler, niceleme ve özdeşlik mantığını kapsar. ${ }^{1}$ Yaygınlaşmış modern mantıkta "gerçekte var olmayan nesnelere gönderme yapan önermelerin doğruluk değeri yoktur, dolayısıyla modern mantıkta bu tür önermelere yer yoktur.” ${ }^{2}$ Bu durum modern mantığın iki temel öndayanağına dayanmaktadır. ${ }^{3}$ Birinci temel öndayanak, nicelemenin yapıldığı tanım kümesinin hiçbir zaman boş küme olamayacağıdır. İkinci temel öndayanak ise var olan nesnelerin yalnızca nicelemenin yapıldığı tanım kümesini göstereceğidir.

Bu durum, biçimsel mantık dizgesinde bir takım doğruluk değeri sapmalarını ve çıkarım düzen dışılıklarını serimler. ${ }^{4}$ Bu yaygın problemleri iki önemli ve birbirileriyle ilintili başlıkta ifade edebiliriz. İlk sorun, sezgisel olarak geçerli olan ancak modern mantıkta kendine yer bulamayan önermeler ve çıkarımlarda ortaya çıkmaktadır. Bu durum ifade edilemezlik problemi olarak adlandırılabilir. Örneğin, "Dünya’nın yörüngesinde Vulkan Gezegeni’ne bağlı herhangi bir sapma gözlemlenmemiştir” önermesi doğru bir önermedir, çünkü "Vulkan” diye bir gezegen olmadığından Dünya’nın yörüngesinde adı geçen gezegene bağlı herhangi bir sapma gözlemlenmeyecektir. Dolayısıyla, bu önerme ifade edilebilir ve doğru bir önermedir. Fakat modern biçimsel mantığın öndayanaklarından ötürü bu önerme ifade edilemez. İkinci sorun ise modern mantıkta geçerli olup, sezgisel olarak geçerli olmayan çıkarımlardır. Bu durum çıkarım düzen dışılı̆̆ı problemi olarak adlandırılabilir. Örneğin, "Pegasus uçar” önermesinden "Pegasus vardır" çıkarımı modern mantıkta geçerli bir çıkarımdır. Bunun sebebi tümel ve tikel niceleyicilerin nesnelere varlık yükü atfetmeleridir. Dolayısıyla, anlamsal olarak doğruluk değerini koruyan çıkarımlar geçerli olarak ifade edilmekle birlikte eğer nicelenmiş nesne gerçekte

1 Teo Grünberg, Sembolik Mantık El Kitabı Cilt 1: Temel Mantık (Ankara: ODTÜ G.v., 2017), s. 9-10 ve Donald Kalish, Richard Montague, Gary Mar, Logic: Techniques of Formal Reasoning (Oxford: Oxford University Press, 1980), s. 44, 105-106, 184.

2 Teo Grünberg, Sembolik Mantık El Kitabı Cilt 2: Özel Mantık Sistemleri (Ankara: METU Press, 2000), s. 43, John Nolt, "Free Logic" (The Stanford Encyclopedia of Philosophy. Sonbahar 2018 Edisyonu. Erişim 12 Ekim 2019), Bölüm 1 .

3 Susan Haack, Philosophy of Logics (Cambridge: Cambridge University Press, 1978), s. 71-72, Graham Priest, An Introduction to Non-Classical Logic (Cambridge: Cambridge University Press, 2008), s. 290-291.

4 Edgar Morscher ve Peter Simons, "Free Logic: A Fifty-Year Past and an Open future." New Essays in Free Logic In Honour of Karel Lambert. Derleyen Morscher, Edgar; Hieke, Alexander (Dordrecht: Kluwer Academic Publishers, 2001), s. 3-4. 
yok ise bu çıkarımlar sezgisel olarak geçerli olmayacaktır. Çünkü, sonuçta "Pegasus" gerçekte var olan bir nesne değildir.

Bağımsız mantıklar olarak tanıtacağımız ve betimleyici özelliklerini sunacağımız yeni bir mantık dizgesi, yukarıda belirttiğimiz sorunlar söz konusu olduğunda benzer problemli ve sezgi-karşıtı sonuçları doğurmazlar. Çünkü Bağımsız Mantıklar, modern mantıkta yer alan tekil terimlerin gönderimde bulunduğu gerçek bir nesnenin var olduğu kabulüne yer vermemesiyle farklılaşan bir mantık dizgesidir. ${ }^{5}$ Böylece yukarıda belirtilen her iki problem için bir çözüm sunar. İlkinde, boş tekil terimlerin geçtiği ifadelere belirli doğruluk değerleri atfedilebileceğini ortaya koyarak ifade edilebilirlik sorununu çözer. İkincisinde ise nesnenin varlığı söz konusu olmadığı için geçerlilik durumuna karşı tatmin edici bir karşı model sunarak bu çıkarımın geçersizliğini gösterir. Bu dizgeyi yaygınlaşmış modern mantıktan ayıran en önemli nokta boş tekil terimlerin geçtiği ifadelerin mantık dizgesi içinde kendine yer bulabilmesi ve dahası boş tekil terimlerin geçtiği bu önermelerden oluşan çıkarımların sezgisel geçersizliğinin biçimsel olarak ifade edilebilmesidir. ${ }^{6}$

Bağımsız mantık terimi ilk defa Karel Lambert tarafından 1960 yılında yazına kazandırılmıştır. Lambert’in varlık öndayanaklarından bağımsız olmak anlamında kullandığı bu ayrışım sözcüğünün ifadesi "tekil ve genel terimlerin var olduklarını belirten, nesnelerin var olma zorunluluğu öndayanağından bağımsız olma durumunu ifade etmek ve bu öndayanaklardan bağımsız olan mantık dizgelerini tanımlamak için kullanılır.” ’

Bu çalışma aşağıda belirtilen bölümlendirme ışığında sunulacaktır. İkinci bölümde modern mantıkta, ifade edilebilirlik ve çıkarım düzen dışılıkları problemleri biçimsel olarak tanıtılacaktır. Ardından, özdeşlik mantığına ek olarak yeni bir mantık değişmezi olan varlık yüklemi tanıtılarak, mantık dizgesi genişletilecektir. Üçüncü bölümde, var olan nesnelere gönderimde bulunmayan terimlerin geçtiği önermeler ve bu önermelerin oluşturduğu argümanların ifade edilebilir olduğu yeni bir mantık dizgesi olan bağımsız mantıkların biçimsel dili tanımlanarak sözdizimsel kuralları betimlenecektir. Dördüncü bölümde bağımsız mantık dizgelerinin tanımlayıcı nitelikleri verilerek anlambilimsel ve kaplamsal yorumlamalarına göre ayrılan çeşitlemeleri tanımlanacaktır. Beşinci Bölümde modern mantığın bir yönelimi olarak varlıksal öndayanaklardan bağımsız mantıkların tarihsel gelişimine değinilecektir. Bu mantık dizgelerinin varlıksal öndayanakları varlık olma niteliğini salt mantıksal zorunluluk olarak değil ontolojik bir olanaklılık olarak ele alarak, boş terimlerin geçtiği önermelerin kaplamsal yorumlamalarını mümkün kılacaktır.

5 Bkz. Karel Lambert, "The Definition of E! in Free Logic," Abstracts: The International Congress for Logic, Methodology and Philosophy of Science (Stanford: Stanford University Press, 1960) ve Ermanno Bencivenga, "Free Logics" Handbook of Philosophical Logic. Derleyenler Dov Gabbay and F. Guenthner, 2. Edisyon, Cilt 5, (Dordrecht: Kluwer, 2002).

6 Priest, An Introduction to Non-Classical Logic, s. 296 ve Karel Lambert, Free Logic: Selected Essays (Cambridge: Cambridge University Press, 2003), s. 132.

7 Karel Lambert, "Free Logics.” The Blackwell Guide to Philosophical Logic. Derleyen Lou Goble, (Oxford: Blackwell Publishing, 2001), s. 258-259. 


\section{Modern Mantıkta Öndayanaklar, Niceleme, Özdeşlik ve Varlık Mantığı}

Mantıkta varlık adları, nesnelerin var olduklarına dair varlıksal yük taşır. Bu, kullanılan terimler için belirli bir nesnenin var olduğu öndayanağıdır. Diğer bir deyişle, tekil ve genel terimler yalnızca var olan nesnelere gönderimde bulunur. Bu durum mantığın iki temel öndayanağına dayanmaktadır. İlk temel öndayanak, nicelemenin yapıldığı tanım kümesinin hiçbir zaman boş küme olamayacağıdır. Bu öndayanağa göre önermeler içinde geçen yüklemlenen nesnelerinin gerçekte var olması bir zorunluluğudur. İkinci temel öndayanak ise var olan nesnelerin yalnızca nicelemenin yapıldığı tanım kümesini göstereceğidir. Bu öndayanağa göre yüklemler mantığında biçimselleştirilen tümel ya da tikel niceleme yalnızca var olan nesneleri kapsayabilir. "Her şey ölümlüdür” önermesini ele aldığımızda tümel niceleyicinin tanım kümesinde yer alacak olan nesneler içerisinde "Sokrates", "Venüs" gibi nesneler yer alırken, "Pegasus" ve "Gulyabani" nesneleri yer alamaz.

Modern mantığın öndayanakları, Gottlob Frege ve Bertrand Russell tikel genelleme niceleyicisini varlık niceleyecisi olarak kabul etmelerinde dayanmaktadır. ${ }^{8}$ Frege'ye göre "var olmak” bir yüklem değil, nesneleri tikel genelleyen bir nicelemedir. ${ }^{9}$ Dahası, ünlü mantıkçı W.v.O. Quine da benzer şekilde niceleyicileri varlığın tanımı olarak almış ve bir slogan olarak "var olmak bağlı değişkenin bir değeri olmaktır” biçiminde ifade etmiştir. ${ }^{10}$ Her ne kadar doğal dillerdeki niceleyicilerin biçimsel dillerde her zaman varlıksal bir yüke sahip olduğu kabul edilse de, var olmayan nesneler söz konusu olduğunda bu durumun sezgisel olarak anlaşılması pek de kolay değildir. Bunun en açık nedeni doğal dilde sıklıkla var olmayan nesneler hakkında konuşmamız, onlara çeşitli nitelikleri ve özellikleri yükleyebilmemizdir. Örneğin kurgusal karakterler, mitolojik yaratıklar veya varsayımsal gezegenler gibi bazı adlar ya da tekil terimler varlıksal bir yük taşımamaktadır, ama yine de onlar hakkında bir takım özellikleri ifade eden önermeler kullanırız.

Modern mantıkta yer alan tekil adlar var olan nesnelere işaret etmesi gerektiği için varlık yükü taşımayan ya da en azından varlığı bilinmeyen (belki de şüpheli olan) nesneleri içeren ifadelere uygulanmasında bir takım sıra dışılıklar ortaya çıkmaktadır. Varlık yükü taşımayan, gerçek evrende herhangi bir nesneye gönderme yapmayan terimler boş tekil terim ya da boş ad olarak tanımlanırlar. Giriş bölümünde tanıttığımız ifade edilemezlik problemini ve çıkarım düzen dışılığı problemini biçimsel olarak göstermek için öncelikle yüklemler, niceleme ve özdeşlik

8 Bkz. Gottlob Frege, "Function and Concept." (1891) Translations from the Philosophical Writings of Gottlob Frege (Oxford: Blackwell, 1980), s.37-38; Gottlob Frege, "On Sense and Reference." (1892) The Frege Reader (Oxford: Blackwell, 1997), s.187-188; Bertrand Russell, The Principles of Mathematics (Cambridge: Cambridge University Press, 1903), s.57, 91-92.

9 Scott Soames, The Analytic Tradition in Philosophy, Volume 1: The Founding Giants (Princeton: Princeton University Press, 2014), s.60-61. Soames varlık kavramının yüklem olamayacağı önermesini "sadece Frege tarafından değil Kant ve Russell tarafından da yapılmış önemli bir hata olduğunu” belirtir. Ayrıca "niceleyicilerin doğal dillerdeki kullanımının sadece var olan nesnelere gönderme yapmasını” da bir hata olarak nitelendirir. A.g.e. s.61.

Aktaran Priest, An Introduction to Non-Classical Logic, s.296. 
mantığı üzerine genişletilen varlık mantığının biçimsel dizgesini gösterelim. ${ }^{11}$ İlk olarak, "vardır" ifadesinin biçimsel mantık dilindeki çözümlemesiyle başlayacağız. Örneğin,

(1) Venüs Gezegeni vardır

(2) Vulkan Gezegeni vardır

önermelerindeki "vardır" sözcüğü yüklemler mantığında yeni bir mantık değişmezi işlevindedir ve varlık değişmezi olarak adlandırılır. Bu değişmez "E!" işaretiyle gösterilir. ${ }^{12}$ Varlık değişmezi tekil terimlerle birlikte yalın bir önerme oluşturdukları için birli-yüklemdir. Buna göre

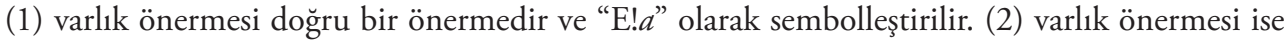
yanlış bir önermedir ve sembolleştirmesi "E! $b$ ” dir. Benzer şekilde temel önerme eklemeleriyle oluşturulabilecek birleşik önermeler de varlık değişmeziyle ifade edilebilir.

(3) Pegasus var değildir

ve

(4) Pegasus yoktur

birleşik önermeleri “ $\neg \mathrm{E}$ !c” biçiminde sembolleştirilebilir.

Varlık değişmezi olan “E!” tikel niceleyici ve özdeşlik değişmezi üzerinden de tanımlanabilir. ${ }^{13}$

(5) $\quad \mathrm{E} !:=\exists x(x=t)$

Böylece varlık değişmezi, özdeşlik değişmezini içeren niceleme mantığına yeni bir mantık değişmezi olarak eklenerek, yeni bir mantık dizgesi tanımlanır. Varlık mantığının biçimsel dili aşağıdaki tabloda ifade edilmiştir.

\begin{tabular}{|c|c|}
\hline Mantık Değişmezi & Sembolleştirmesi \\
\hline Temel önerme eklemleri & 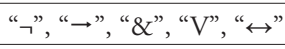 \\
\hline n-li Yüklem temsilcileri & "F, G, H, ..." \\
\hline Ad temsilcileri & $" a, b, c, \ldots "$ \\
\hline Niceleyiciler & “ $\forall "$, " $\exists "$ \\
\hline Özdelik Değişmezi & "=" \\
\hline Varlık Değişmezi & "E!" \\
\hline
\end{tabular}

Şimdi varlık mantığı dizgesi çerçevesinde giriş bölümünde belirttiğimiz problemlerin biçimsel gösterimlerini ifade edelim. İlk sorun ifade edilemezlik problemi olarak tanımladığımız sezgisel olarak geçerli olan ancak modern mantıkta kendine yer bulamayan önermeler ve bu önermelerin geçtiği çıkarımlardı. Öncelikle, önermelerin içinde geçen ad temsilcilerinin gerçekte

11 Bu biçimsel dizge Grünberg, Sembolik Mantık El Kitabı Cilt 2: Özel Mantık Sistemleri, s.40 ve Morscher ve Simons, "Free Logic: A Fifty-Year Past and an Open future.", s. 4-6 kaynaklarından temel alınmıştır.

12 Jaakko Hintikka, “Towards a Theory of Definite Descriptions." Analysis 19 (1959): s. 79-85 ve Lambert, "Free logic and the concept of existence", s. 134-136.

13 Nolt, "Free Logic", Bölüm 1. 
var olan herhangi bir nesneye gönderme yapamayacağı için bu ifadeler modern mantıkta ifade edilemiyordu. Artık varlık mantığında varlık değişmezi üzerinden bu nesnelerin var olup olmadığını ifade edebiliriz. Ancak, yine doğruluk değeri sapması hala mevcuttur çünkü modern mantıkta yine de bu önermeler doğru veya yanlış herhangi bir doğruluk değerine sahip olamazlar. İkinci temel problem olan çıkarım düzen dışılığı problemi ise kendisini korumaktadır. Buna göre tümel ve tikel niceleyiciler nesnelere varlık yükü atfettikleri için yüklemler mantığında biçimsel olarak geçerli bazı çıkarımlar sezgisel olarak geçerli değildir.

(6) Gulyabani hayal ürünüdür

önermesinden

(7) Öyle bir $x$ nesnesi vardır ki $x$ Gulyabani'dir.

çıkarımı geçerli bir çıkarımdır. Çünkü hakkında nitelemede bulunulan nesne, modern mantığın varlıksal öndayanakları gereği var olmalıdır. Bu önermenin mantıksal biçimi, "g", “Gulyabani” nesnesini ve “ $H$ ”, "hayal ürünüdür" yüklemini ifade etmek üzere

(8) $\mathrm{Hg}$

biçiminde sembolleştirilebilir. Bu ifadeden yapılacak mantıksal çıkarım "g vardır" önermesini imler ve imlenen bu ifadenin mantıksal biçimi şudur:

(9) $\exists x(x=g)$

Dolayısıyla, $\mathrm{H} g \vdash \exists x(x=g)$ çıkarımı mantık yasasına dayanan geçerli bir mantıksal çıkarımdır, çünkü " $g$ vardır” önermesi, varlıksal öndayanakları gereği her yorumlamada doğrudur fakat "Gulyabani” adı gerçekte var olan herhangi bir nesneye gönderimde bulunmaz. Biçimsel olarak " $\Phi$ ” ifadesinden " $\exists x(x=\tau)$ " tikel genellemesine geçerlidir. Ancak yukarıdaki belirtilen varlık önermesinde "Gulyabani” adının herhangi bir gönderimi olmadığı için çıkarım geçerli olmayacaktır. Dolayısıyla, mantık yasasına göre geçerli olan bir çıkarım sezgisel olarak geçerli değildir.

\section{Mantıksal Adlar, Varlıksal Öndayanaklar, Varlık Yükü ve Bağımsız Mantiklar}

Biçimsel mantığın varlıksal kabulleri gereği her tekil terim var olan bir nesnesinin adıdır. Daha genel olarak varlıkları belirli nesnelere gönderme yapan tekil terimler mantıksal ad olarak kabul edilir. Ne var ki yüklemler ve niceleme temeli üzerine özdeşlik ve varlık değişmezlerinin eklenmesiyle oluşturulan mantık dizgesinde "Gulyabani", "Pegasus", "Vulcan" gibi var olan bir nesneye gönderimde bulunmayan adlar kullanılamaz. ${ }^{14}$ Gerek mantık dilinin kapsayıcılı̆̆ı, gerek gündelik doğal dilde geçerli olan ifadelerin temellendirildiği ve sembolleştirildiği biçimsel dizgeleri için bu cümleler hiç kuşkusuz ifade edilebilir olmalıdır. ${ }^{15}$ Çünkü hem ifade edilemezlik

14 Bkz. Grünberg, Sembolik Mantık El Kitabı Cilt 2: Özel Mantık Sistemleri, s.43.

15 Nolt, "Free Logic", Bölüm 1 ve Morscher ve Simons "Free Logic: A Fifty-Year Past and an Open future", s. 1-3. 
hem çıkarım düzen dışılığı problemleri biçimsel mantık için doğruluk değeri sapmaları ve karşısezgi yarattıkları için üstesinden gelinmesi gereken önemli problemlerdir. Bu problemlerin üstesinden gelebilmek için varlık mantıksal değişmezinin olduğu mantık dizgesini var olmayan nesneleri de ifade edecek bir biçimde genişleterek yeni bir mantık dizgesi ortaya konulmuştur. Bu yeni mantık dizgesi varlıksal öndayanaklardan bağımsız olma anlamında modern mantıktan ayrışarak Bă̆ımsız Mantık olarak adlandırılmıştır.

Şimdi bu yeni mantık dizgesinin ifade edilemezlik ve çıkarım düzen dışılığ problemlerine getirdiği çözümleri, Bağımsız mantıkların tikel terimlerin yorumlanması, genel terimlerin yorumlanması ve çıkarım kuralları temelinde ele alalım.

\section{Tekil Terimlerin Kaplamsal Yorumlaması}

Varlık olma yükünden bağımsız olmayı sağlamanın belki de en kolay yolu nicelemenin tanım kümesini sadece var olan nesneler kümesiyle sınırlandırmaktır. ${ }^{16}$ Bunu yaparken değer kümesinin olanaklı olan ancak zorunlu bir özalt kümesi olmayan bir alt kümesini ortaya koymaktır. ${ }^{17}$ Buradaki değer kümesi, önceki öndayanakla uygun olarak var olan en az bir nesneyi kapsayacak biçimde boş olmayan bir küme olma özelliğini sürdürmektedir.

Özdeşlik mantığında var olan bir nesneye gönderimde bulunmayan "Pegasus”, "Gulyabani”, "Vulkan Gezegeni" gibi adlara kaplamsal anlam vermek amacıyla var olmayan ama olanaklı nesnelere başvurulur. Burada, adın kaplamı işaret ettiği nesnelerin kendisi iken, önermelerin kaplamsal anlamı bu önermelerin doğruluk değeri olacaktır. Kuşkusuz "Pegasus”, "Gulyabani”, "Vulkan Gezegeni” adlarının gerçek dünyada gönderimde bulunduğu nesneler yoktur. Ancak bu adlar tanımlanamaz veya zihinde belirli özellikleri tasarlanamaz değildir. Gerek doğal dillerde çeşitli ve sık kullanımları, gerek belirli görüngülerin açıklanmasında bu türden var olmayan ancak olanaklı nesnelere sıklıkla başvurulmaktadır. Dolayısıyla her ne kadar bu adlar kaplamsal birer nesne olmasalar da bu adların geçtiği önermelerin zorunlu olarak kaplamsal anlama sahip olmayacakları çıkarılamaz. Buna dayanarak var olmayan nesnelerin olanaklı nesneler olduğu sonucu çıkarabiliriz. Benzer şekilde her var olan nesne de olanaklı birer nesnedir.

Bu noktada gerçekte var olan nesneler ile gerçekte var olmayan nesneler arasında bir ayrım yapabilmek için ve gerçekte var olmayan, olanaklı nesneler salt olanaklı nesneler olarak ifade edilecektir. Yalnızca var olan nesnelerden oluşan evreni tanımlayan küme iç evren tanımlanır ve $E_{\text {iç }}$ olarak ifade edilir. Salt olanaklı nesnelerden oluşan evreni tanımlayan küme dı̧̧ evren olarak tanımlanır ve $E_{\mathrm{d} ı ̧ ̧}$ olarak ifade edilir. ${ }^{18}$ Buna göre tekil terimlerin varlıksal özelliklerine göre iç evren ve dış evren arasında iki temel bağıntı vardır:

(i) Tüm olanakları nesneleri ifade eden küme iç evren ve dış evrenin birleşiminden oluşan $E$ kümesidir, açık bir ifadeyle $E=E_{\mathrm{iç}} \cup E_{\mathrm{d} \text { ış }}$ tır. Ancak $E$ boş küme olamaz. Başka bir ifade ile $E \neq \emptyset$.

16 Bkz. Bencivenga “Truth, Correspondence, and Non-Denoting Singular Terms." Philosophia 9 (1980), s.223 ve Priest, An Introduction to Non-Classical Logic, s. 295.

17 Grünberg, Sembolik Mantık El Kitabı Cilt 2: Özel Mantık Sistemleri, s.43.

18 A.g.e., s.43-44. 
(ii) Yalnızca var olan nesnelerden oluşan evren ve salt olanaklı nesnelerden oluşan evren

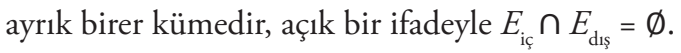

Örneğin, a: Pegasus, b: Sokrates, c: Vulkan, d: Venüs tekil terimlerini göstermek üzere $E_{\mathrm{iç}}=$ $\{\mathrm{a}, \mathrm{c}\}$ ve $E_{\text {dı̨̣ }}=\{\mathrm{b}, \mathrm{d}\}$ dir.

Buradan hareketle "E! $\tau$ ” varlık önermesinin kaplamsal yorumlaması ${ }^{19}$

$E_{\mathrm{ic}}=\left\{\alpha_{1}, \alpha_{2}, \ldots, \alpha_{\mathrm{n}}\right\} \quad$ öyle ki $\alpha_{1}, \alpha_{2}, \ldots, \alpha_{\mathrm{n}}$ var olan nesneleri

$E_{\mathrm{d} \mathfrak{s} s}=\left\{\beta_{1}, \beta_{2}, \ldots, \beta_{\mathrm{n}}\right\} \quad$ öyle ki $\beta_{1}, \beta_{2}, \ldots, \beta_{\mathrm{n}}$ salt olanaklı nesneleri

$E=\left\{\alpha_{1}, \alpha_{2}, \ldots, \alpha_{\mathrm{n}}, b_{1}, b_{2}, \ldots, b_{\mathrm{n}}\right\}$ tüm olanaklı nesneleri ifade eder.

(*) “E! $\tau$ ” önermesi eğer $\tau \in E_{\mathrm{icc}}$ ise doğru; eğer $\tau \notin E_{\text {iç }}$ ise yanlıştır.

\section{Genel Terimlerin Kaplamsal Yorumlaması}

İç evreni $E_{\mathrm{icc}}=\left\{\alpha_{1}, \alpha_{2}, \ldots, \alpha_{\mathrm{n}}\right\}$ olan bir yorumlamada $\forall \tau \Phi \tau$ tümel genelleme önermesinin doğru olması için $\Phi \tau$ 'in $E_{\text {iç }}$ 'deki tüm özellemelerinin $\Phi \alpha_{1}, \alpha_{2}, \ldots, \alpha_{\mathrm{n}}$ doğru olması gerekir. Yine İç evreni $\varepsilon_{\text {iç }}=\left\{\alpha_{1}, \alpha_{2}, \ldots, \alpha_{\mathrm{n}}\right\}$ olan bir yorumlamada $\exists \tau \Phi \tau$ tikel genelleme önermesinin doğru olması için $\Phi \tau$ 'in $E_{\text {iç }}$ 'deki özellemeleri $\Phi \alpha_{1}, \alpha_{2}, \ldots, \alpha_{\mathrm{n}}$ önermelerinden en az bir özellemesinin doğru olması gerekir. ${ }^{20}$

Örneğin, "Her şey vardır" tümel önermesi olan

(10) $\forall x \mathrm{E} ! x$

yukarıdaki a: Pegasus, b: Sokrates, c: Vulkan, d: Venüs nesneleri söz konusu olduğunda, "E!b" ve "E! d" için doğru doğruluk değerine sahiptir. Dolayısıyla $E_{\text {iç }}$ yorumlamasının tüm özellememerinde doğru için " $\forall x$ E! $x$ ” tümel önermesi doğrudur.

Benzer biçimde, "En az bir şey vardır” tikel önermesi olan

(11) $\exists x \mathrm{E} ! x$

ifadesi “E! b" veya "E! d’ için doğrudur. Dolayısıyla, $E_{\text {iç }}$ yorumlamasın en az bir özellemesi doğru olduğu için " $\exists x$ E! $x$ ” tikel önermesi doğrudur.

\section{Çıkarım Kuralları}

Bağımsız mantığın çıkarım kuralları modern mantıkta geçerli olup, sezgisel olarak geçerli olmayan çıkarımların neden geçersiz çıkarımlar olduğuna dair kaplamsal bir yorumlamada karşı

19 Priest, An Introduction to Non-Classical Logic, s. 295.

20 Grünberg, Sembolik Mantık El Kitabı Cilt 2: Özel Mantık Sistemleri, s. 45. 
bir örnek sunmalıdır. ${ }^{21}$ Bunu gerçekleştirmek için boş tekil terimlerin geçtiği çıkarımları geçersiz kabul ederek, ya da diğer bir deyişle gerçek nesnelere gönderimde bulunan tekil terimlerin iç evrenin bir elemanı olmasını bir öncül kabul ederek, çıkarım kurallarını sınırlandırır. ${ }^{22}$

Örneğin, modern mantıkta geçerli olan biçimsel tümel özelleme kuralı

$\forall x A \vdash A(\tau / x)$

Bağımsız mantıkta geçerli değildir.

Benzer biçimde tikel genelleme kuralı

$A(\tau / x) \vdash \exists x A(\tau / / x)$

Bağımsız mantıkta geçerli değildir.

Böylece çıkarım düzen dışılığı problemine bir çözüm sunulmuş olur. Örnek olarak

(6) Gulyabani hayal ürünüdür

önermesinden

(8) Gulyabani vardır

çıkarımının Bağımsız Mantık’ta geçersiz bir çıkarım olduğunu karşı bir örnekle gösterebiliriz.

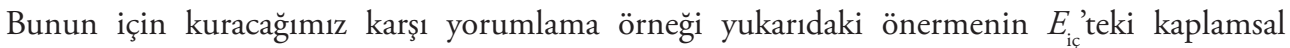
yorumlamasına bağlı olacaktır. "Gulyabani” nesnesi salt olanaklı bir nesne olduğundan dolayı $E_{\text {dı̧̣ }}$ kümesinde yer alacak, yani $g \in E_{\text {dı̧̣ }}$, ve $E_{\text {iç }} \cap E_{\text {dı̧̣ }}=\emptyset$ olduğundan dolayı gerçekte var olan nesneleri tanımlayan $E_{\text {iç }}$ kümesinde yer almayacaktır. Öyleyse $g \notin E_{\text {iç }}$ olacaktır. Böylelikle karşı $\mathrm{Hg}$ önermesi doğru olmasına rağmen $\left(^{*}\right)$ gereği $\exists x(x=g)$ önermesi yanlış olacaktır. yorumlama örneği "Gulyabani vardır” önermesinin yanlışlığını ortaya koyar.

Buradan hareketle, Bağımsız Mantığın Sınırlandırılmış Tümel Özelleme ve Sınırlandırılmış Tikel Genelleme Kuralları aşağıdaki gibi belirtilebilir: ${ }^{23}$

Sınırlandırılmış Tümel Özelleme Kuralı

$\forall x A, \mathrm{E} ! \tau \vdash A(\tau / x)$

Sınırlandırlmış Tikel Genelleme Kuralı

$A(\tau / x), \mathrm{E} ! \tau \vdash \exists x A(\tau / / x)$

21 Priest, An Introduction to Non-Classical Logic, s.299.

22 Nolt, "Free Logic", Bölüm 1.

23 Nolt, "Free Logic", Bölüm 2.2. 
Sonuç olarak varlık mantığı ve özdeşlik mantığı arasındaki ilişki şöyle belirlenir: "Varlık mantığında geçerli olan her önerme aynı zamanda özdeşlik mantığında da geçerlidir. Ama tersi doğru değildir. Özdeşlik mantığında geçerli olan bazı önermeler varlık mantığında geçersizdir.” ${ }^{24}$

\section{Bağımsız Mantık Dizgeleri}

Yukarıda tikel terimlerinin, genel terimlerini ve çıkarım kurallarını tanımladığımız Bağımsız Mantık dizgesi $\mathcal{L}$ üç bileşenden oluşacak biçimde aşağıdaki gibi tanımlanır: ${ }^{25}$

(i) $\mathcal{L}$ dizgesi tekil terimleri bakımından varlıksal öndayanaklardan bağımsızdır.

(ii) $\mathcal{L}$ dizgesi genel terimleri bakımından varlıksal öndayanaklardan bağımsızdır.

(iii) $\mathcal{L}$ dizgesinin niceleyicileri varlıksal varsayıma sahiptir.

$\mathrm{Bu}$ anlamda bağımsız mantıklar kaplamsal yorumlamalarına göre dizgesel ayırt edici nitelikleri bakımından ayrışırlar. Diğer bir deyişle, boş tekil terim içeren yalın önermelerinin doğruluk değeri alıp alamamasına göre dizgesel türlerine ayrılırlar. Bu nedenle bağımsız mantıklar dizgesi üzerine konuşurken üç tür bağımsız mantıktan söz edilir. Bunlar negatif dizgeler, pozitif dizgeler ve nötr dizgelerdir. Negatif dizgede boş tekil terim içeren tüm yalın önermeler yanlıştır. ${ }^{26}$ Pozitif dizgede dizgede boş tekil terim içeren ve "E! $\tau$ " biçiminde olmayan en az bir yalın önerme doğrudur. ${ }^{27}$ Nötr (veya değersiz) dizgede boş tekil terim içeren ve "E! $\tau$ ” biçiminde olmayan tüm yalın önermeler doğruluk dĕgersizdir. ${ }^{28}$

Yukarıdaki tanımlamadan da anlaşılacağı üzere bağımsız mantık dizgesi, tek bir mantık dizgesinden ziyade çoklu bir mantıklar dizgesidir ve genel olarak Betimleyici Mantıklar olarak adlandirilırlar.

\section{Pozitif Bağımsız Mantık Dizgesi}

Pozitif bağımsız mantık dizgesinin yalın önermeleri kaplamsal yorumlamalarında belirli

24 Grünberg, Sembolik Mantık El Kitabı Cilt 2: Özel Mantık Sistemleri, s. 48. Krş. Lambert, "Free Logics”, s.263 ve Morscher ve Simons, "Free Logic: A Fifty-Year Past and an Open future.", s. 6-7.

25 Morscher ve Simons, "Free Logic: A Fifty-Year Past and an Open future.", s. 2.

26 Bkz. Rolf Schock, Logics without Existence Assumptions (Stockholm: Almqvist \& Wiksell, 1968), Bencivenga "Truth, Correspondence, and Non-Denoting Singular Terms." Philosophia 9 (1980) ve Nolt "Free Logic", Bölüm 3.1 .

27 Bkz. Hughes Leblanc, “Truth Value Semantics for a Logic of Existence.” Notre Dame Journal of Formal Logic 12 (1981) ve Nolt, "Free Logic”, Bölüm 2.1. ve 3.2.

28 Bkz. Bas C. van Fraassen, "Singular Terms, Truth Value Gaps and Free Logic," Journal of Philosophy 63 (1966) ve Nolt, "Free Logic”, Bölüm 3.3.Buradaki dizgesel tanım Nolt’un yaklaşımıdır. Mosrcher'in tanımında "doğruluk değerine sahip olmayan en az bir tekil önerme" olarak geçmektedir. Morscher ve Simons, "Free Logic: A Fifty-Year Past and an Open future", s. 2. 
olumlayıcı özelliklere ya da niteliklere sahip olabilirler. Bu durum olanaklı doğru bir yorumlama olarak kabul edilirse, örneğin;

(9) Pegasus yoktur ve Pegasus uçar

vb. önermeler

(10) $\neg \mathrm{E} ! p \& \mathrm{U} p$.

biçiminde ifade edilerek doğru doğruluk değerine sahip olur.

Pozitif Bağımsız Mantık Dizgesinin Aksiyomları ${ }^{29}$ aşağıdaki gibidir:

(A1) $A \rightarrow \forall x A$

(A2) $\forall x(A \rightarrow B) \rightarrow(\forall x A \rightarrow \forall x B)$

(A3) $\forall x \mathrm{E} ! x$

(A4) $\forall x A \rightarrow(\mathrm{E} ! \tau \rightarrow A(\tau / x))$

(A5) $\forall x(x=x)$

(A6) $\tau=v \rightarrow(A \rightarrow A(\tau / / v))$

(A7) $\forall x A(x / \tau), \quad$ eğer $A$ bir aksiyom ise.

(A3) ve (A4) aksiyomları Bağımsız mantıklara özgün aksiyomlardır, diğer aksiyomlar ise özdeşlik ve varlık mantığın aksiyomları ile ortaktır. (A4) aksiyomu, varlık yüklemi “E!” tanımı gereği tikel niceleyici ve özdeşlik değişmezleri kullanılarak da ifade edilebilir ${ }^{30}$

$\left(\mathrm{A} 4^{*}\right) \forall x A \rightarrow(\exists v(v=\tau) \rightarrow A(\tau / x))$

Bu aksiyom dizgesi tek çıkarım kuralı olan Modus Ponens ile tamamlanır

$$
A \rightarrow B, A \vdash B
$$

Aksiyomatik dizgelere ek olarak, Pozitif bağımsız mantık doğal çıkarım dizgelerinde eşdeğer biçimde ifade edilebilir. Bir önceki bölümde belirttiğimiz sınırlandırılmış tümel özelleme ve tikel genelleme kurallarına ek olarak, varlık değişmezi “E!” yardımıyla tümel genelleme kuralı

$A(\tau / x), \mathrm{E} ! \tau \vdash \forall x A$

biçimindedir. Burada " $\tau$ ” yeni bir terim olduğunda ve $A$ içinde geçmediğinde varlık değişmezi kaldırılır ve tümel nicelenmiş önerme çıkarılır.

29 Lambert, Free Logic: Selected Essays, s.48, Morscher ve Simons, "Free Logic: A Fifty-Year Past and an Open future", s. 8 ve Nolt, "Free Logic", Bölüm 2.1.

30 Nolt, a.g.e. 
Bu dizgede " $\tau$ ” yeni bir terim olmak üzere sınırlandırılmış tikel özelleme kuralı ${ }^{31}$

$\exists x A, A(\tau / / x) \vdash \mathrm{E} ! \tau$

şeklinde ifade edilir.

\section{Negatif Bağımsız Mantık Dizgesi}

Negatif bağımsız mantık dizgesinin yalın önermeleri kaplamsal yorumlamalarında hiç bir olumlayıcı özelliğe ya da niteliğe sahip olamazlar. Bu durum tüm yorumlamalarda olanaksız olarak kabul edildiğinden dolayı var olmayan nesnelere yüklenen özelliklerin ve niteliklerin ifade edildiği önermelerin tamamı yanlış olacaktır. ${ }^{32} \mathrm{Bu}$ dizgenin ayrıt edici aksiyomu olan

(A-) $A(\tau / x) \rightarrow \mathrm{E} ! \tau$

Pozitif Bağımsız Mantık dizgesi aksiyomlarına eklenerek Negatif Mantık Dizgesi Aksiyomları elde edilmiş olur. ${ }^{33}$ (A-) aksiyomu negatif bağımsız mantık dizgesine özgün bir aksiyomdur ve sadece olumlu nitelik yüklemine sahip terimlerin var olabileceğini ifade eder. Örneğin

(9) Pegasus yoktur ve Pegasus uçar

önermesi (A-) aksiyomuna uyarlanırsa, aksiyomun art bileşeni "E!p" ifadesi olumsuzlacanacağından aksiyom koşulunun ön bileşeni " $\mathrm{U} p$ ” de olumsuzlanmış olur. Böylece salt olanaklı nesnelerin yalın önermeleri her zaman yanlış olur. ${ }^{34}$

\section{Nötr Bağımsız Mantık Dizgesi}

Nötr (değerliksiz) bağımsız mantık dizgesi negatif dizgenin aksine boş tekil terimlerin geçtiği önermelerin kaplamsal yorumlamalarının tümünde yanlış değil, ne doğru ne de yanlış doğruluk değeri alır. Diğer bir deyişle, var olmayan nesnelere gönderme yapan terimlerin geçtiği önermelere doğru veya yanlış doğruluk değeri atfetmez. Böylece nötr bağımsız mantıkta doğruluk değeri boşlukları oluşmaktadır ve bu boşluklar üstdeğerlemeler (supervaluations) olarak ifade edilir. ${ }^{35}$ Buradan kısmen karşı sezgisel olan şu durum çıkar: "Nötr Bağımsız Mantıklar dizgelerindeki tüm teoremlere birer üstdeğerleme atfedilerek geçerli teoremler haline getirilebilir." ${ }^{36}$

\section{Modern Mantığın Bir Yönelimi Olarak Bağımsız Mantıklar}

Bir araştırma ve çalışma alanı olarak yaklaşık 70 yıllık bir tarihinden söz edeceğimiz bağımsız mantık dizgelerinin ortaya konulmasındaki temel amaç boş tekil terimlerin modern mantığın söz dağarcığına girmesiyle ortaya çıkan varlık öndayanaklarına dayalı ifade sorunlarına ve

31 Teo Grünberg, Sembolik Mantık El Kitabı Cilt 2: Özel Mantık, s. 49.

32 Bkz. Schock, Logics without Existence Assumptions.

33 Morscher ve Simons, "Free Logic: A Fifty-Year Past and an Open future", s. 7.

34 Priest, An Introduction to Non-Classical Logic, s. 299 ve Nolt, "Free Logic”, Bölüm 3.1.

35 Nolt, "Free Logic", Bölüm 3.3. Bkz. Bas C. van Fraassen, "Singular Terms, Truth Value Gaps and Free Logic".

36 Nolt, a.g.e., Bölüm 3.4. 
çıkarım düzen dışılıklarına çözüm getirmektir. Bu bakımdan ilk ortaya konulan bağımsız mantık dizgeleri, varlık öndayanaklarıyla ilgili bu sorunları çözmek amacıyla H.S. Leonard ve ardından Jaakko Hintikka tarafından ortaya konulan dizgelerdir. ${ }^{37}$ İlksel bir çözüm olarak, varlık bildiren mantık değişmezi özdeşlik ve tikel niceleyici üzerinden tanımlanmış ve böylelikle bu sorunun üstesinden gelinmiştir. Daha sonra Karel Lambert "bağımsız mantık” terimini "tikel veya genel terimlerine göre varlık öndayanaklarından bağımsız mantık” olarak tanımlamıştır. ${ }^{38}$

Lambert'in bu tanımı ortaya koymasındaki amaç var olmayan nesneleri niteleyen (örneğin " $x$ Marslıdır”, “ $x$ kendisine özdeş değildir”, “ $x$ ışık hızından daha hızlıdır” gibi) yüklemlerin var olan herhangi bir nesne ile sağlanabilirlik koşulunu yerine getirmemesidir. Hintikka ve Leblanc bu probleme ilk çözüm olarak varlık yüklemini öne sürmeden tikel genelleme kuralı uygulamasını sadece nesne değişkenlerine kısıtlayarak ve nesne değişmezlerini bu kuralın uygulama alanı dışında bırakarak çözmüşlerdir. [...]Bağımsız mantık dizgelerinin ilk aksiyomlaşıırması Lambert tarafından yapılmışır ve Negatif Bağımsız Mantık dizgesidir. Bu dizgede varlık yüklemi ve özdeşlik yüklemi bulunmamaktadır. Benzer zamanlarda Rolf Schock her iki yüklemi de içeren negatif mantık dizgesini ortaya koymuştur. Pozitif Bağımsız mantığın ilk aksiyomlaştırma dizgesi Lambert tarafından ortaya konulmuştur. [...] Eğer dış tanım kümesi olan dış evrenin bazı tekil terimlere karşılık gelen bir varlık atfetmesi istenilmiyorsa kaplamsal yorumlama fonksiyonu kısmi bir fonksiyona dönüşür. Bu durumda tekil terimlerin kaplamsal boşlukları olacağı görülür. Üstdeğerleme yorumlamaları bu soruna getirilebilecek çözümlerden biridir. Nötr Bağımsız Mantıklar özgün biçimiyle van Fraassen tarafından ortaya konulmuştur. ${ }^{39}$

\section{Sonuç}

$\mathrm{Bu}$ çalışmanın temel amacı yaygınlaşmış modern mantıktan farklılaşan bağımsız mantık dizgelerinin tanıtılması ve özelliklerinin betimlenmesidir. Modern mantığın bir yönelimi olarak, tikel ve genel terimlerine göre varlıksal öndayanaklardan bağımsızlığı, bu mantık dizgelerinin ayrıcı niteliği olarak ele alınarak dil ve nesne ontolojisi bağlamında değerlendirilecektir.

Düşünce edimi olarak var olmayan nesneler tasavvur edilebilir, zihinde canlandırabilir, düşüncenin konusu yapılabilir. Her ne kadar nesnelerin var olmamaları, bu nesnelere dair zihinsel edimleri varlığın bir sorusu yapsa da gerçek söylemde belirli niteliklerin atfedilebileceği salt olanaklı nesnelerin tanımlanamaması anlamına gelmemektedir. Varlık sorusu, düşüncenin ifade edildiği dil sorusu olarak benzer başka sorunlara da işaret etmektedir. Düşüncenin tutarlı ve eksiksiz bir dizge içerisinde mantık dili ile ifade edilmesi çabaları sıklıkla mantık ontolojisinin temellendirici

37 Leonard, H. S. "The Logic of Existence." Philosophical Studies 7 (1956): 49-64 ve Hintikka, "Towards a Theory of Definite Descriptions.” Analysis 19 (1959): 79-85.

38 Lambert, "The Definition of E! in Free Logic".

39 Morscher ve Simons, "Free Logic: A Fifty-Year Past and an Open future", s. 24-25. 
gerekçelendirmesi olmuştur. ${ }^{40}$ Filozoflar sıklıkla adlar ile yüklemler ve bunların doğruluk ve anlam yorumlamalarını temellendirecek bir takım varlık öndayanakları öne sürmüşlerdir. Ancak özellikle varlık mantığı bağlamında söz konusu olan ifade edilebilirliğin sınırlarına ulaşıldığında ortaya daha kapsayıcı bir mantık dizgesinin ortaya konulması bu çalışmada değindiğimiz temel zorlukların üstesinden gelinebilmesi açısından oldukça yararlıdır. ${ }^{41}$

Önermelerin kaplamsal yorumlaması, içinde geçen tekil ve genel terimlerin bütünselliği sonucu doğru veya yanlış belirli bir doğruluk değeridir. İfadelerin içinde geçen bu terimlerin gönderimsel doğruluk yorumlamasını belirleyecektir. Ancak nesnelerin salt varlıksal olanaklılığı söz konusu olduğunda, önermelerin kaplamsal yorumlamaları olanaklılığın türüne göre ayrışacaktır. Bu bakımdan iki tür olanaklılık vardır. İlk tür olanaklılık, mantıksal olanaklılıktır. Mantıksal olanaklılık sadece doğruluk değerleri yorumlamasına bağlıdır, dolayısıyla mantıksal doğru (ya da mantıksal yanlış) ve olumsal önermeleri ifade etmek için kullanılır. Örneğin, mantık değişmezlerinin ve önerme eklemlerinin anlamları sabit tutulduğunda " $P \mathrm{~V} \neg P$ ” önermesi olanaklı her yorumlamada doğru doğruluk değerine sahip iken, “ $P \& \neg P$ ” önermesi olanaklı her yorumlamada yanlış doğruluk değerine sahiptir. " $P$ ” önermesi ise olumsaldır, yani belirli olanaklı yorumlamalarda doğru doğruluk değerine, belirli olanaklı yorumlamalarda yanlış doğruluk değerine sahip olabilir. İkinci tür olanaklılık, metafiziksel veya varlıksal olanaklılık kavramıdır. Buna göre bir nesnenin varlığı, zorunlu veya olanalıklı olarak var olmasıyla açıklanır. "Vulkan Gezegeni” nesnesi olduğumuz olanaklı evren yorumlamasında var olan bir nesne değil iken, en azından olanaklı bir evren yorumlamasında pekala var olabilirdi. Dolayısıyla "Vulkan Gezegeni" olanaklı bir nesnedir. Böylece bu terimin geçtiği önermeler olumsal veya zorunlu doğrular (veya yanlışlıklar) ifade edebilecektir. Bu ayrım Bağımsız Mantıkların temel ontolojik öndayanağıdır. Daha açık bir ifade ile varlık olma niteliği ontolojik bir olanaklılık olarak kabul edilmektedir. $\mathrm{Bu}$ bakımdan kaplamsal yorumlama sadece mantık yasalarının doğruluk değerleri üzerinden yapılmayacaktır. ${ }^{42}$ Ayrıca, nesne kategorilerini gerçekte var olan ile salt olanaklı olan nesneler üzerinden ayrıştırarak, bu terimlerin geçtiği önermelerin bütünselliği korunacak ve kaplamsal yorumlama yapilabilecektir.

Böylece, boş tanım kümeleri kaplamsal yorumlamaları açıklamak amacıyla kullanılabildiğinde, boş tekil terimler de olanaklı hale gelir. Ancak bu koşulun tersi için yeterli sağlamlıkta bir temellendirme bulunmamaktadır. Diğer bir deyişle, boş tekil terimlerin var olduğu bir dizgede her zaman boş tanım kümelerinin bulunması gerekmez.. Buna göre mantık, düşüncenin ve akıl yürütmenin geçerliliğini belirleyen özellikleri ve kuralları ortaya koymayı amaçlayan a priori bir çalışma alanı olarak ortaya çıkar. Ancak aynı zamanda mantık gündelik ve gerçek hayattaki uslamlamalara uygun bir biçimde argümanların geçerliliğini ve sağlamlığını ortaya koymalıdır. Bir argümanın geçerliliğini sınarken ya da argümanı oluşturan önermelerin doğruluk değerini

40 Kapsamlı bir tartışma için Bkz. Scott Soames, The Analytic Tradition in Philosophy, Volume 1: The Founding Giants, s. $60-64 ; 280-287 ;$ 598-604.

41 Bkz. Grünberg, Sembolik Mantık El Kitabı Cilt 2: Özel Mantık Sistemleri, Bölüm 4.

42 Bkz. Grünberg, Sembolik Mantık El Kitabı Cilt 2: Özel Mantık Sistemleri, Bölüm 4 ve Priest, An Introduction to Non-Classical Logic, s.297. 
belirlerken her zaman söylemin bağlamında kastedilen nesneler tanım kümesi olarak kabul edilir. Bağımsız mantıkların söylem bağlamına getirdiği yenilik ise gerçekte var olmayan terimlerin salt olanaklı nesneler yorumlamasıyla bu bağlama katılarak hem önermelerin ifade edilebilirliğini sağlayacak hem de boş terimlerin geçtiği argümanların çıkarımlarını sezgilerle örtüşür biçimde geçerli ya da geçersiz kılacaktır.

Öyleyse, Bağımsız mantık, mantık yasalarını veya kurallarını modern mantıkta olduğu gibi değiştirilemez ya da dokunulmaz olarak ele almaz. Bu mantık, önermelerin doğruluğunu veya argümanların geçerliliğini ortaya koyarken karşılaşılan sezgi karşıtı durumların ya da basit anlamıyla ifade edilemezliğin önüne geçmeyi amaçlamaktadır. Bu kuralları kısıtlamak veya kısmen değiştirmek, boş terimlerin varlıksal öndayanaklarını açık bir biçimde ortaya koyar. Bu bağlamda modern mantığın bir yönelimi olarak Bağımsız Mantıklar gelecek vaat eden mantık dizgeleridir.

Finansal Destek: Yazar bu çalışma için finansal destek almamıştır.

\section{Kaynaklar}

Bencivenga, Ermanno. “Truth, Correspondence, and Non-Denoting Singular Terms." Philosophia 9 (1980): 219-229.

Bencivenga, Ermanno. "Free Logics." Handbook of Philosophical Logic. Derleyenler Dov Gabbay and F. Guenthner, 2. Edisyon, Cilt 5, 147-196. Dordrecht: Kluwer, 2002.

Frege, Gottlob. "Function and Concept." (1891) Translations from the Philosophical Writings of Gottlob Frege içinde. Çeviren Peter Geach. Derleyenler Peter Geach ve Max Black. Oxford: Blackwell, 1980.

Frege, Gottlob. "Function and Concept." (1891) Translations from the Philosophical Writings of Gottlob Frege içinde. Çeviren Peter Geach. Derleyenler Peter Geach ve Max Black. Oxford: Blackwell, 1980.

Frege, Gottlob. "On Sense and Reference" (1892) The Frege Reader içinde. Derleyen Michael Beaney. Oxford: Blackwell, 1997,

Grünberg, Teo; Onart, Adnan; Grünberg David; Turan, Halil. Mantık Terimleri Sözlü̈̆̈u, Genişletilmiş 3. Basım. Ankara: METU Press, 2003.

Grünberg, Teo. Sembolik Mantık El Kitabı Cilt 2: Özel Mantık Sistemleri. Ankara: METU Press, 2000.

Grünberg, Teo. Sembolik Mantık El Kitabı Cilt 1: Temel Mantık. Ankara: ODTÜ G. v., 2017.

Haack, Susan, Philosophy of Logics. Cambridge: Cambridge University Press, 1978.

Hintikka, Jaakko. "Towards a Theory of Definite Descriptions." Analysis 19 (1959): 79-85.

Kalish, Donald; Montague, Richard; Mar, Gary. Logic: Techniques of Formal Reasoning, 2. Edisyon. Oxford: Oxford University Press, 1980.

Lambert, Karel. "The Definition of E! in Free Logic," Abstracts: The International Congress for Logic, Methodology and Philosophy of Science içinde. Stanford: Stanford University Press, 1960.

Lambert, Karel. "Free Logics." The Blackwell Guide to Philosophical Logic. Derleyen Lou Goble, 258-279. Oxford: Blackwell Publishing, 2001.

Lambert, Karel. Free Logic: Selected Essays. Cambridge: Cambridge University Press, 2003.

Leblanc, Hughes. "Truth Value Semantics for a Logic of Existence." Notre Dame Journal of Formal Logic 12 (1981): 153-68.

Leonard, H. S. "The Logic of Existence." Philosophical Studies 7 (1956): 49-64. 
Morscher, Edgar ve Simons, Peter "Free Logic: A Fifty-Year Past and an Open future." New Essays in Free Logic In Honour of Karel Lambert. Derleyen Morscher, Edgar; Hieke, Alexander, 1-36. Dordrecht: Kluwer Academic Publishers, 2001.

Nolt, John. "Free Logic.” The Stanford Encyclopedia of Philosophy. (Sonbahar 2018 Edisyonu) https://plato. stanford.edu/archives/fall2018/entries/logic-free/. Erişim 12 Ekim 2019.

Priest, Graham. An Introduction to Non-Classical Logic: From If to Is. Cambridge: Cambridge University Press, 2008.

Russell, Bertrand. The Principles of Mathematics. Oxford: Routledge, 1903[2010].

Soames, Scott. The Analytic Tradition in Philosophy, Volume 1: The Founding Giants. Princeton: Princeton University Press, 2014.

Schock, Rolf. Logics without Existence Assumptions, Stockholm: Almqvist \& Wiksell, 1968.

van Fraassen, Bas C. "Singular Terms, Truth Value Gaps and Free Logic," Journal of Philosophy 63 (1966): 481-495. 